\title{
Experimental Study on Influence of Chemical Corrosion on Mechanical Property of Fissured Granite
}

\author{
Fan Zhang, ${ }^{1}$ Tao He, ${ }^{1}$ JunjieKang, ${ }^{1}$ and Dawei $\mathrm{Hu} \mathbb{D}^{2}$ \\ ${ }^{1}$ School of Civil Engineering, Architecture and Environment, Hubei University of Technology, Wuhan 430068, China \\ ${ }^{2}$ State Key Laboratory of Geomechanics and Geotechnical Engineering, Institute of Rock and Soil Mechanics, Chinese Academy \\ of Sciences, Wuhan 430071, China
}

Correspondence should be addressed to Dawei Hu; dwhu@whrsm.ac.cn

Received 21 November 2020; Revised 7 February 2021; Accepted 25 February 2021; Published 12 March 2021

Academic Editor: Kai Yao

Copyright (c) 2021 Fan Zhang et al. This is an open access article distributed under the Creative Commons Attribution License, which permits unrestricted use, distribution, and reproduction in any medium, provided the original work is properly cited.

\begin{abstract}
The effect of chemical corrosion and natural joints on the damage characteristics and strength of rock masses is highly important for the construction of rock engineering and energy extraction. Therefore, the intact granite is processed into prefabricated fissured granite specimens with a fissure angle of $0^{\circ}, 30^{\circ}$, and $45^{\circ}$. Chemical corrosion tests are then performed on the prefabricated fissured granites. The $\mathrm{pH}$ of the solution gradually becomes neutral; the mass loss of the granite specimens and the mineral compositions of the fissure surface are measured and analyzed. The scanning electron microscopy (SEM) and uniaxial compression tests are performed on the granite specimens after chemical corrosion. After chemical corrosion, the surface of the fissure becomes loose. The various mineral components of the specimens have been changed to different degrees or converted into other mineral components. The peak strength and elastic modulus of the prefabricated fissured granites with the three fissure angles present a clear decrease, as the time of chemical corrosion increases. The stress intensity factors at the fissured tip are also analyzed. The stress intensity factors of the specimens with a fissure angle of $0^{\circ}, 30^{\circ}$, and $45^{\circ}$ decrease from $0.017,0.35$, and 0.84 to $0.013,0.30$, and $0.74 \mathrm{MPa} \cdot \mathrm{m}^{1 / 2}$, respectively, as the time of the chemical corrosion increases. And the chemical corrosion has the largest effect on the intensity factors of the specimens with a fissure angle of $45^{\circ}$ among the three angles. These experimental results could improve the understanding of the long-term stability of underground engineering in the multifield coupling environment.
\end{abstract}

\section{Introduction}

Due to the function of crustal movement and weathering, a large number of fissures with different sizes are induced inside rocks. In the underground of rock engineering such as underground energy storage, oil extraction, gas extraction, and geothermal extraction, the initiation, propagation, and penetration of these fissures are closely related to the instability and destruction of rock engineering.

The natural fissures of rocks are the decisive factor for the stability of underground rock engineering. A large number of experimental studies have focused on the physicomechanical properties of fissured granite, such as ultrasound characteristic strength, elastic modulus, and fracture behaviors [1-4]. In addition to the traditional analysis of mechanical parameters of fissured granites, some scholars confirm that the fracture criterion is related to the properties of the rock, prefabricated cracks, and types of loading [5]. Simultaneously, secondary cracks and wing cracks are observed $[6,7]$ during the uniaxial and biaxial compression tests by using rock-like models with prefabricated fissures. In the tip of crack, the tensile crack and petal crack [8] are observed by an experimental study on marbles with a 3-D surface flaw. In order to supplement previous research results, crack propagation $[9,10]$ and coalescence $[11,12]$ with prefabricated fissures have been extensively studied by experimental and simulation research. For example, Wu et al. [13] distinguished coalescence modes of three rock bridges: stretch-stretch, shear-shear, and stretchshear mode by the DIC and CT methods. The simulation of granites with prefabricated joints by PFC shows that granites usually generate tensile fracture with low confining pressure, tensile-shear mixed fracture with medium confining pressure, and shear fracture with high confining pressure [14]. The simulated crack growth, coalescence, and type are highly 
consistent with the experimental results by using the method of finite element with unstructured mesh of tetrahedral element [15]. Simultaneously, there is also research on the mechanical properties and expansion modes of granite with two kinds of joints. Rezania et al. [16] conducted the numerical simulation and experimental research on granite with two side cracks and an opening with a tunnel; the results showed that the fissured angle has a great influence on the mechanical properties, stress distribution, and crack propagation of granite. Yang et al. [17] summarized the propagation and aggregation mode of cracks in the stage of loading through the experimental and simulation study on granite with two holes and a fissure.

In addition, in the underground engineering constructions such as coal mining, the geological repository of radioactive wastes and tunnels, surrounding rocks, will be inevitably immersed in the environment of saturated water because of the groundwater. The aggressive ions in the water will affect the mechanical properties of surrounding rocks and the stability of the tunnel, which weakens the mechanical property of the rocks [18]. Therefore, it is of great importance to study the mechanical properties of rocks under the action of chemical corrosion.

In recent years, many scholars have carried out a series of studies on the physical and mechanical properties of various rock materials after corrosion by water and chemical solutions. Corrosive solutions, such as $\mathrm{NaCl}$ and $\mathrm{NaOH}$, obviously have a great influence on the rate of crack growth of quartz [19]. Dunning et al. [20] analyzed the role of the chemical environment in frictional deformation, including stress corrosion cracking and grinding. The failure mechanism of rock mass after chemical corrosion has become a hot topic. For example, Karfakis and Akram [21] carried out the strain energy index and fracture toughness tests on three kinds of rocks under five environments and researched the mechanism of modification of rock characteristics under the chemical corrosion. Sausse et al. [22] conducted the research on the fissured permeability of granites under the action of water and rock and discussed the evolution law of permeability of granites. Min et al. [23] proposed a model about the mechanical and transport characteristics of fissured rock. Croizé et al. [24] conducted the uniaxial compression test on crushed calcite to investigate the physical properties of rocks and their evolution during fault zone processes. Yu et al. [25] proposed the damage variables to be used to describe the corrosion damage. The development of computer technology has also accelerated the progress of scientific research on rock mechanics [26, 27]. For example, the parallel bond stress corrosion model [28] is obtained by adding the damage rate law, which can well simulate the chemical corrosion reaction of rock under the action of aqueous solution. And this model can also be used to predict the macrogradation of mechanical properties caused by chemical corrosion and simulate the evolution process of microdamage [29]. Mohtarami et al. [30] developed an extended finite element code that could reproduce the singularity in anisotropic and uneven environments after chemical corrosion.

However, the previous research results mostly focus on the mechanical and physical properties of intact rock masses after chemical corrosion. Considering the complexity of the underground environment and natural joints, the rock mass is inevitably affected by the chemical-stress coupling. Therefore, it is essential to carry out research on the mechanical characteristics of fissured granites with various angles after chemical corrosion. This paper carries out research on the physical and mechanical properties of fissured granite after chemical corrosion $(0,30,60$, and 90 days) and analyzes the variations of mineral composition and microstructure of fissured granites after chemical corrosion. Simultaneously, the stress intensity factors of the fissured tip after chemical corrosion are calculated and analyze the change mechanism of the stress intensity factors at the fissured tip. The results can provide a theoretical basis for the stability analysis of underground engineering.

\section{Test Preparation}

2.1. Specimen Preparation. The rock specimens in the experiment are sampled from Yueyang, Hunan province, China, with a dense structure and good macroscopic homogeneity. And the natural density is $2.6 \mathrm{~g} / \mathrm{cm}^{3}$. The average mass fractions of the main mineral components are quartz (30\%), sodium feldspar (19.67\%), and potassium feldspar (24.49\%), and the specimen also contains a small amount of biotite $(11.71 \%)$, chlorite $(7.18 \%)$, and illite $(6.95 \%)$. The granite specimens are processed into cylindrical standard specimens of $\varphi 50 \times 100 \mathrm{~mm}$. The processed accuracy of the specimens (including the parallelism, straightness, and perpendicularity of the granites) is controlled by the suggested methods of the International Society of Rock Mechanics and Rock Engineering (IRSM). Therefore, the surface of the specimens is smooth and without obvious defects. The Mohs hardness of granites is about 7 [31], which is a species of hard granite. Since the cutting thickness of fissured specimens is large, prefabricated fissures adopt the water-jet cutting technique to process the specimens [32]. The length of the prefabricated fissure is $20 \mathrm{~mm}$, the width is $1 \mathrm{~mm}$, and the maximum depth of cutting is $50 \mathrm{~mm}$. The prefabricated fissures, respectively, have inclinations with $\alpha=0^{\circ}, 30^{\circ}$, and $45^{\circ}$ (Figure 1).

2.2. Specimen Processing. Groundwater contains amounts of various ions such as $\mathrm{Na}^{+}, \mathrm{Ca}^{2+}, \mathrm{SO}_{4}^{2-}, \mathrm{Mg}^{2+}, \mathrm{Cl}^{-}$, and $\mathrm{HCO}_{3}^{-}$. When granites are immersed in the environment of ionic solution, multiple mineral ingredients will react with chemical solution such as decomposition reaction, oxidationreduction reaction, and single displacement reaction. And the chemical reactions deteriorate the mechanical property of granites. However, the contents of $\mathrm{Na}^{+}$and $\mathrm{Cl}^{-}$in the ionic solution are more [33]. Therefore, the granite specimens are immersed in a glass vessel, which contains an oversaturated $\mathrm{NaCl}$ solution with the concentration of $5.4 \mathrm{~mol} / \mathrm{L}$ and $\mathrm{pH}=$ 2. The vessel is sealed with Vaseline to prevent evaporation of water. The test, respectively, selects 30,60, and 90 days as immersed time. To ensure the accuracy of the experimental results, the temperature of a test is a constant temperature $\left(22^{\circ} \mathrm{C}\right)$. During the immersion of the specimens, this paper measured the change of the $\mathrm{pH}$ value of the solution and the 


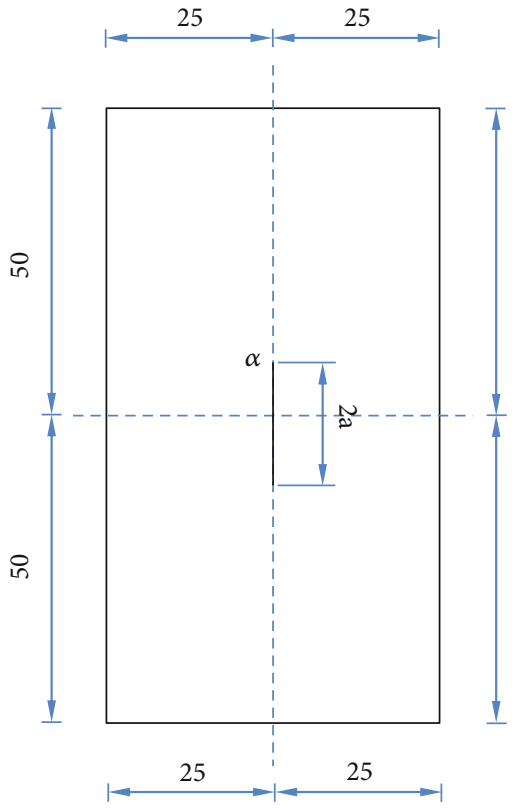

(a)

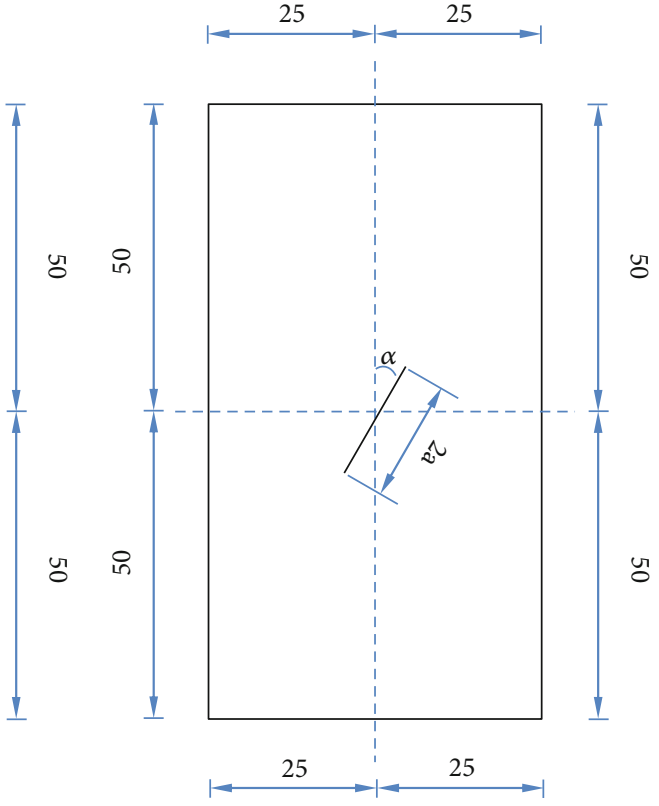

(b)

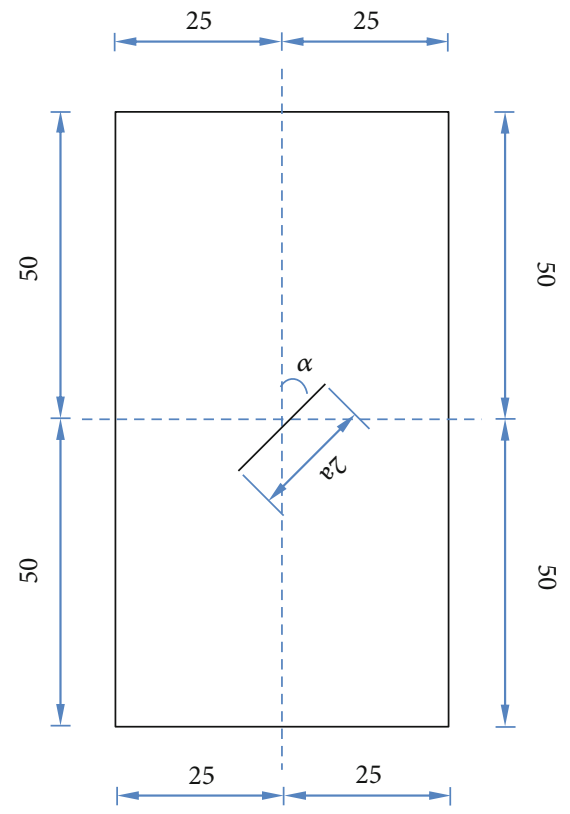

(c)

Figure 1: Prefabricated fissured specimen with different inclinations: (a) specimen with $\alpha=0^{\circ}$, (b) specimen with $\alpha=30^{\circ}$, and (c) specimen with $\alpha=45^{\circ}, 2 \mathrm{a}=20 \mathrm{~mm}$.

quality of the specimens. To ensure the accuracy of the specimens on quality measurement and reduce random errors, after the specimens are taken out, they are dried at $105^{\circ} \mathrm{C}$ in an electric drying oven with constant temperature and the specimens are completely dried for 24 hours. Then, the quality of specimens is measured.

2.3. Test Equipment and Test Process. The uniaxial compression test is completed using a Thermo-Hydro-MechanicalChemical (THMC) coupling test system in this paper [34], which includes a triaxial pressure chamber, an antiforce framework with high strength, an electrohydraulic servo pump with high pressure, a microcomputer system, a strain monitoring with acquisition system, and accessory in Figure 2.

The test process of this article is as follows. The fissured specimens with $\alpha=0^{\circ}, 30^{\circ}$, and $45^{\circ}$ after chemical corrosion for $0,30,60$, and 90 days are pasted axial strain gauges and radial strain gauges on both sides of the plane corresponding of cylindrical shaft of specimens. Then, specimens after treatment are put into the triaxial stress chamber, which connects with strain monitoring with the acquisition system. The test 


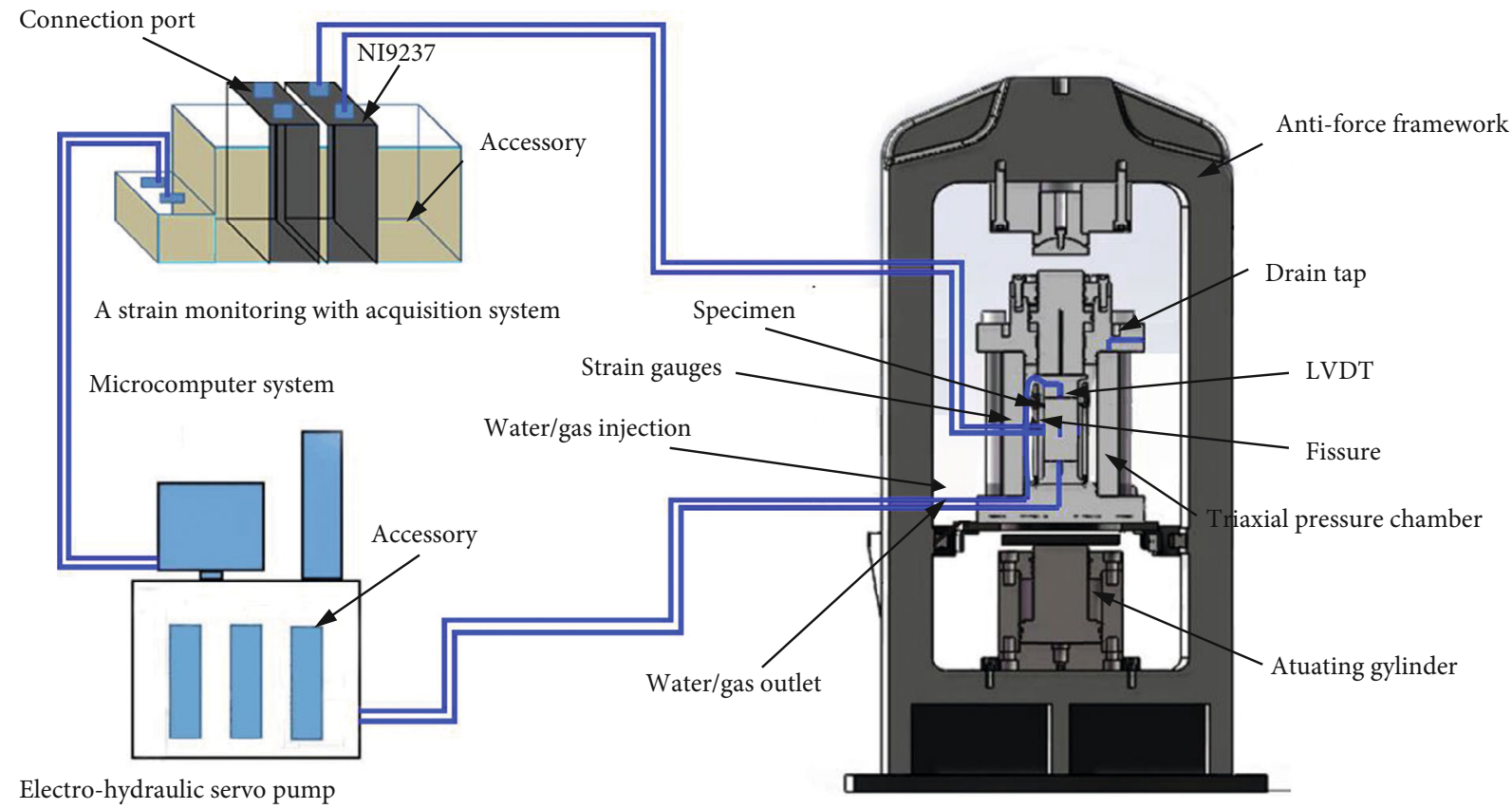

FIGURE 2: THMC coupling test system (after [34]).

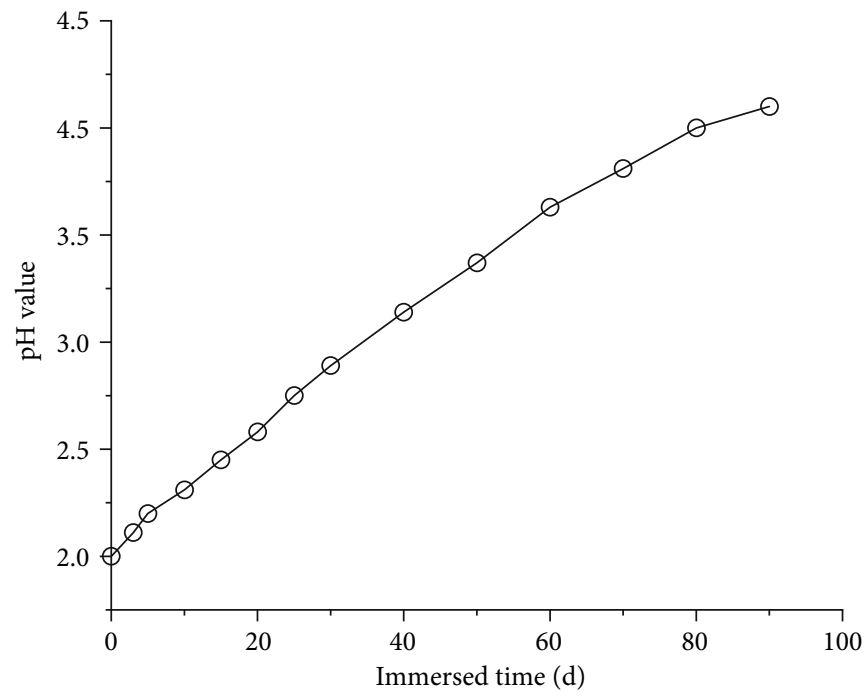

Figure 3: Variation curve of the $\mathrm{pH}$ value with the change of immersed time.

is a uniaxial compression test, the axial force loading is applied under the control mode of axial displacement, and the loading rate is $0.01 \mathrm{~mm} / \mathrm{min}$.

\section{Experimental Results}

3.1. Chemical Corrosion for Prefabricated Fissured Granite. After the chemical corrosion, the $\mathrm{pH}$ value of the solution gradually increases with the increase of the immersed time, and the increasing rate in the stage of initial immersion is large and then gradually flattens out (Figure 3). Figure 4 shows the mass loss of the specimens, which undergoes a rapid decrease to a gradual balance. Because the active mineral content of the initial granite surface is relatively high,
$\mathrm{H}^{+}$ions are quickly consumed in the chemical solution; as the reaction progresses, the granite surface active minerals decrease, resulting in a decrease in the chemical dissolution rate. Simultaneously, the decrease of $\mathrm{H}^{+}$also leads to an increase in the $\mathrm{pH}$ value of the solution, and the $\mathrm{pH}$ value tends to stabilize with the progress of the reaction [35].

In order to analyze the degree of mass loss of prefabricated fissured granites with different inclinations, a mass loss rate $K_{t}$ was defined in Equation (1), $M_{t}$ is the mass of specimens after chemical corrosion, and $M_{0}$ is the initial mass of specimens without chemical corrosion [36].

$$
K_{t}=\frac{\left(M_{t}-M_{0}\right)}{M_{0}} \times 100 \% \text {. }
$$




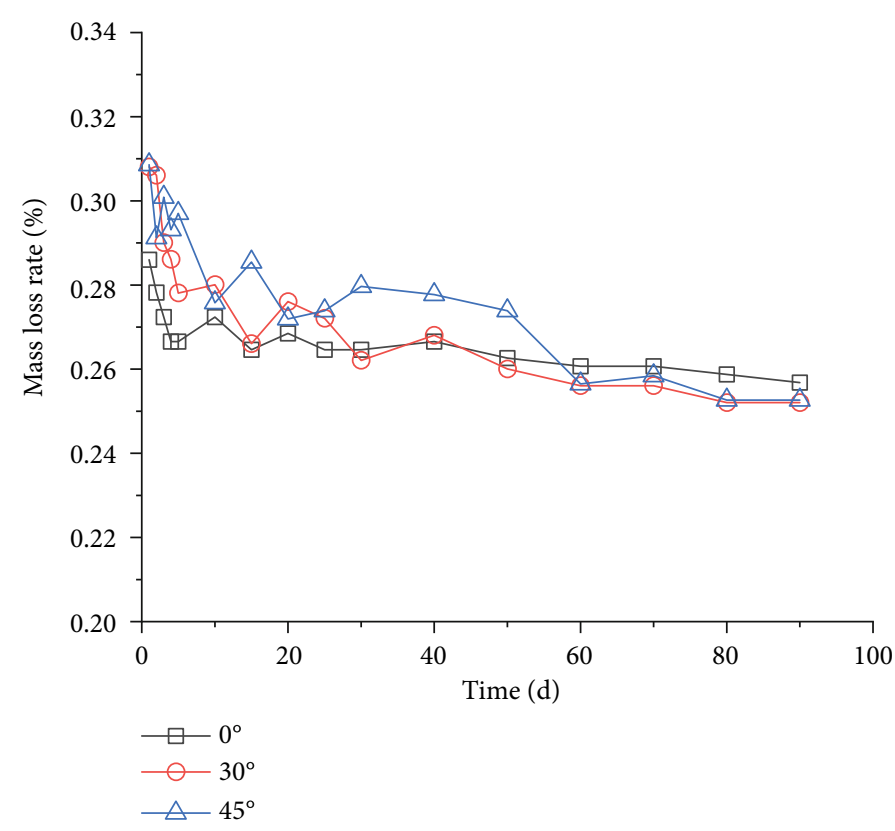

FIgURE 4: Variation curves of mass of specimens under the action of chemical solution.

TABLE 1: Contents of the main minerals of granites during the immersed process.

\begin{tabular}{lcccccc}
\hline \multirow{2}{*}{$\begin{array}{l}\text { Immersed } \\
\text { time (d) }\end{array}$} & \multicolumn{6}{c}{ The contents of main mineral components (\%) } \\
Quartz & $\begin{array}{c}\text { Sodium } \\
\text { feldspar }\end{array}$ & Mica & Chlorite & $\begin{array}{c}\text { Potassium } \\
\text { feldspar }\end{array}$ & Illite \\
\hline 0 & 30.00 & 19.67 & 11.71 & 7.18 & 24.49 & 6.95 \\
30 & 26.19 & 29.53 & 15.23 & 10.04 & 12.91 & 6.11 \\
60 & 34.52 & 27.75 & 11.70 & 6.08 & 14.46 & 5.50 \\
90 & 37.20 & 24.51 & 6.61 & 10.13 & 9.07 & 12.49 \\
\hline
\end{tabular}

To more intuitively analyze the influence of chemical corrosion on the composition of fissured granite, the X-ray diffraction test is proceeded on the surface of granites after chemical corrosion for $0,30,60$, and 90 days, and the results of the content of main minerals are shown in Table 1 and Figure 5. The contents of mica and potassium feldspar show a downward trend during the immersion process, and the decreasing rates of mass percentage are, respectively, $43.55 \%$ and $62.96 \%$ after chemical corrosion for 90 days. This phenomenon is attributed to the reaction of mica and potassium feldspar in an acidic environment (Equations (2) and (3)) $[36,37]$. However, the content of quartz and sodium feldspar slightly ascends with the increase of the immersed time, and the content of chlorite appears to fluctuate. Firstly, the hydrolysis rate of quartz is slower than other types of minerals, and quartz has a lower sensitivity to acidic solutions. Moreover, mica and potassium feldspar will also generate a certain amount of colloidal quartz during the chemical reaction. Secondly, potassium feldspar will produce $\mathrm{K}^{+}$in the process of hydrolysis, and the increase of the concentration of $\mathrm{K}^{+}$is likely to lead to the formation of sodium feldspar [38]. The mass percentage of illite does not significantly change after chemical corrosion for 60 days but significantly increases after chemical corrosion for 90 days, because illite is a kind of potassium-rich mineral, and potassium feldspar can form illite in an acidic environment. Furthermore, after potassium feldspar is corroded in an acidic solution for 90 days, a large amount of $\mathrm{K}^{+}$appear in the corrosive solution, which reacts with sodium feldspar to form illite (Equations (4) and (5)) [39]. In short, after the chemical composition of granites reacts with the acid solution, the chemical composition of granites has changed, leading to the change of the mechanical and physical properties of granites.

The reaction of mica with the acidic solution is written as follows:

$$
\mathrm{KAl}_{3} \mathrm{Si}_{3} \mathrm{O}_{10}(\mathrm{OH})_{2}+10 \mathrm{H}^{+}=3 \mathrm{Al}^{3+}+3 \mathrm{SiO}_{2}+6 \mathrm{H}_{2} \mathrm{O}+\mathrm{K}^{+}
$$

The reaction of potassium feldspar with the chemical solution is written as follows:

$$
\mathrm{KAlSi}_{3} \mathrm{O}_{8}+4 \mathrm{H}^{+}=\mathrm{AI}^{3+}+3 \mathrm{SiO}_{2}+2 \mathrm{H}_{2} \mathrm{O}+\mathrm{K}^{+}
$$

The reaction of formation of illite is written as follows:

$$
\begin{aligned}
3 \mathrm{NaAlSi}_{3} \mathrm{O}_{8}+\mathrm{K}^{+}+2 \mathrm{H}^{+}+\mathrm{H}_{2} \mathrm{O}= & \mathrm{KAl}_{3} \mathrm{Si}_{3} \mathrm{O}_{10}(\mathrm{OH})_{2}+3 \mathrm{Na}^{+} \\
& +6 \mathrm{SiO}_{2}+\mathrm{H}_{2} \mathrm{O}
\end{aligned}
$$

$3 \mathrm{KAlSi}_{3} \mathrm{O}_{8}+2 \mathrm{H}^{+}+\mathrm{H}_{2} \mathrm{O}=\mathrm{KAl}_{3} \mathrm{Si}_{3} \mathrm{O}_{10}(\mathrm{OH})_{2}+2 \mathrm{~K}^{+}+6 \mathrm{SiO}_{2}+\mathrm{H}_{2} \mathrm{O}$

The Scanning Electron Microscope (SEM) tests are performed to observe the microstructure variations of the fissure surface of the granite specimens after chemical corrosion for $0,30,60$, and 90 days, and the results are shown in Figure 6. 


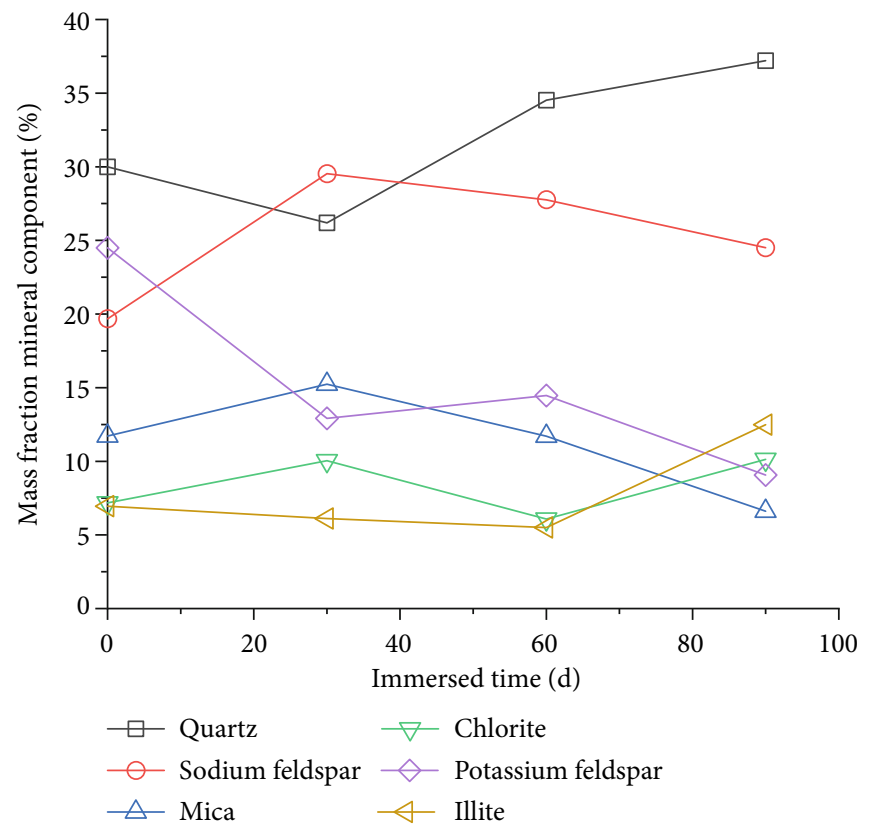

FIGURE 5: Variation curves of the main mineral content during the immersion process.

The fissure surfaces of the granite specimens are damaged to varying degrees after chemical corrosion.

At the initial stage, the surface texture is dense and the cemented surface is complete without chemical corrosion and only a small quantity of fine mineral particles could be observed. The size of crystal particles is clearly distinct (Figure 6(a)). After chemical corrosion for 30 days, local degradation of cemented surface of the specimens can be observed. The microstructure appears loose; fine particles and crystals increase. A lot of small cracks begin to appear, and the edges and corners begin to become smooth (Figure 6(b)). After chemical immersion for 60 and 90 days, the cemented surface is completely destroyed. The surface texture of the fissure becomes loose, and small cracks begin to connect so that the internal edges and corners gradually disappear. A large number of small particles and crystals appear. The structure of honeycomb appears, and secondary pores significantly increase (Figures 6(c) and 7(d)) [36].

\subsection{Mechanical Properties of Fissured Granite after Chemical Corrosion}

3.2.1. Stress-Strain Curves. To study the effect of chemical corrosion on the mechanical property of fissured granites with different inclinations, three kinds of fissured granite specimens with $\alpha=0^{\circ}, 30^{\circ}$, and $45^{\circ}$ are, respectively, immersed in the oversaturated $\mathrm{NaCl}$ solution of $\mathrm{pH}=2$ for $0,30,60$, and 90 days. The uniaxial compression tests are performed on the granite specimens with $\alpha=0^{\circ}, 30^{\circ}$, and $45^{\circ}$ after chemical corrosion for $0,30,60$, and 90 days, and the environment temperature of the test is $22^{\circ} \mathrm{C}$.

Figure 7 shows stress-strain curves for granites with $\alpha=0^{\circ}, 30^{\circ}$, and $45^{\circ}$ without chemical corrosion under the uniaxial compression test. The compaction stage of fissured specimens with $\alpha=45^{\circ}$ has a shorter time by comparing with the specimens with $\alpha=0^{\circ}$ and the specimens with $\alpha=30^{\circ}$, once the microcracks are compacted, which soon enter the elastic deformation stage. Moreover, the specimen with $\alpha=0^{\circ}$ shows ductile failure when it fails. However, when the loading pressure is close to the peak strength of the specimens with $\alpha=30^{\circ}$ and $\alpha=45^{\circ}$, the principal stress drops instantly, which shows a kind of brittle failure.

Due to space constraints, the paper only gives the stressstrain curves of the specimens with $\alpha=0^{\circ}$ after chemical corrosion in Figure 8. According to the stress-strain curves of fissured granite after chemical corrosion, the duration of the initial compaction stage is relatively long for specimens without chemical corrosion. The stress-strain curves of specimens without chemical corrosion in the compaction stage have an obvious concave downward trend. However, the compaction stage of specimens after chemical corrosion is relatively short. Particularly, the specimens are immersed for 90 days. The result shows that the chemical corrosion will shorten the compaction stage of fissured granite and accelerates the destruction speed of the specimens, resulting in a decrease in the peak value of the specimens. The specimens without chemical corrosion basically maintain a linear change before reaching the peak value, and the elastic stage is longer than the specimens after chemical corrosion, and there is no obvious yield point. However, the elastic stage of the specimens becomes shorter after chemical corrosion. The specimens after chemical corrosion for 90 days have the shortest elastic stage. It is indicated that chemical corrosion has damaged the internal structure of the granite, causing the granite to quickly enter the destruction stage. When the stress-strain curve reaches the peak strength, it can be seen that the specimens after chemical corrosion are instantaneously broken, the peak value has a significant drop, and strain even rebounds (specimens after chemical corrosion for 90 days), which presents a brittle failure. However, the 


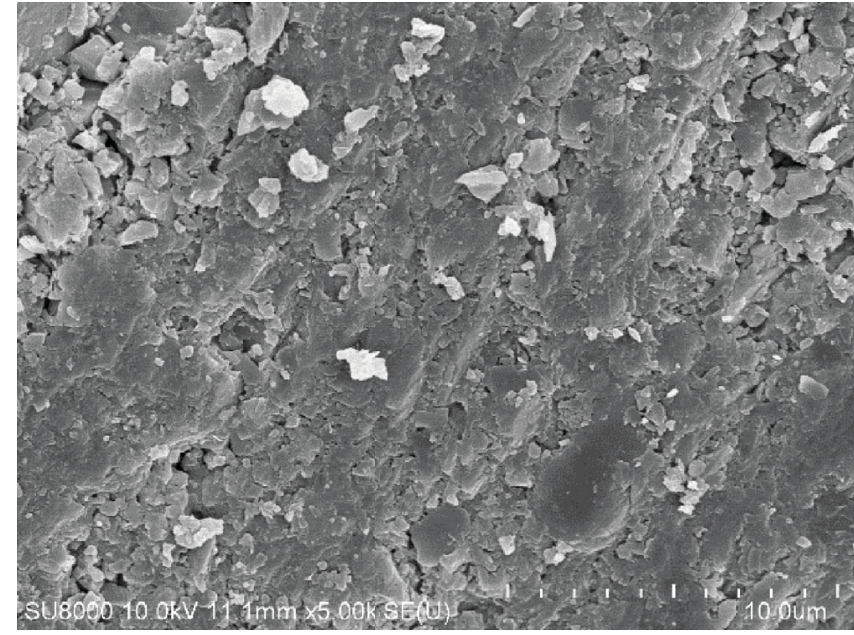

(a)

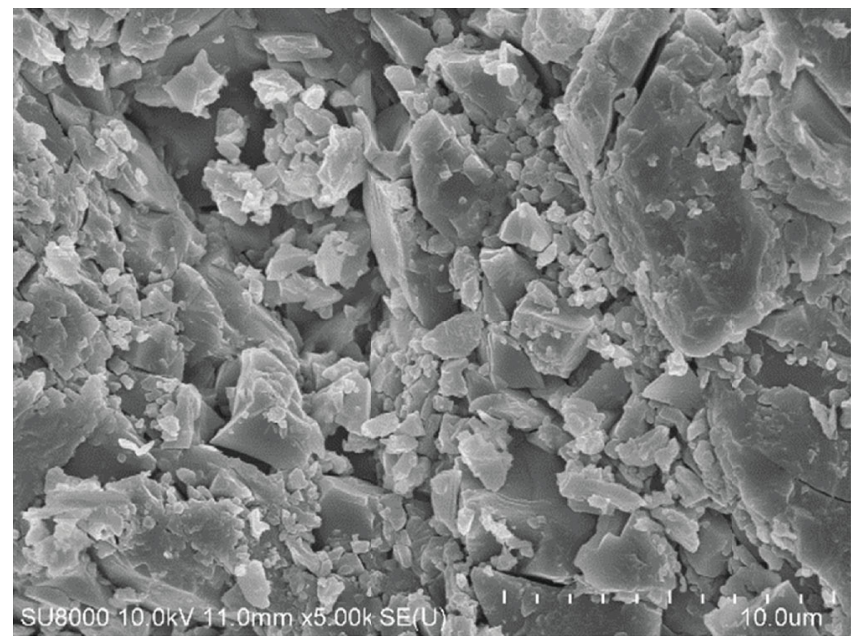

(c)

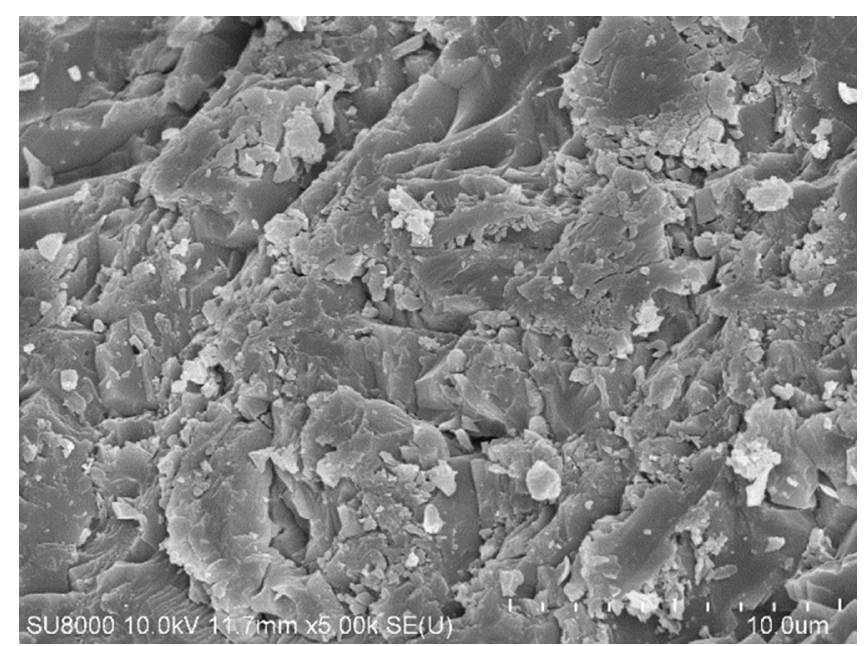

(b)

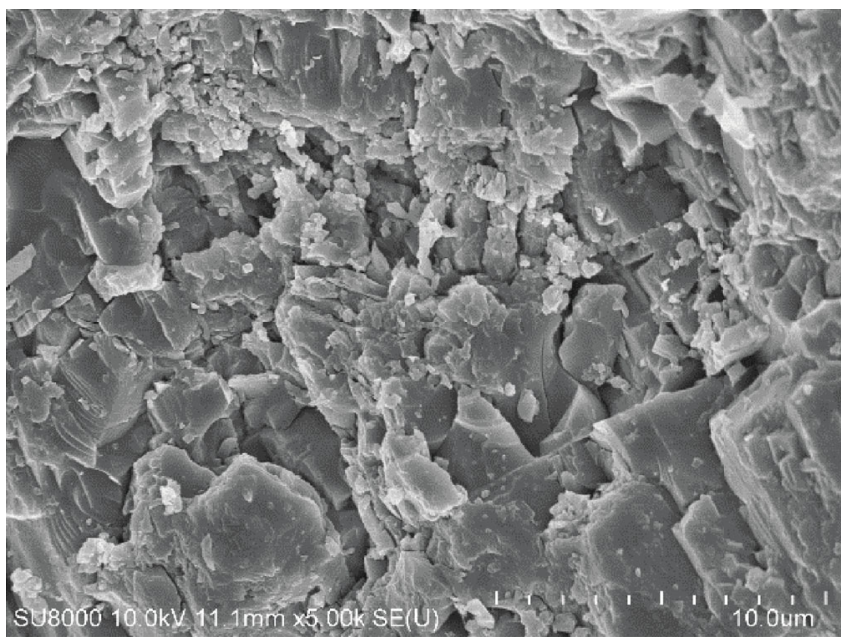

(d)

FIgURE 6: SEM images of fissure surface of granite: (a) without immersion, (b) 30 days, (c) 60 days, and (d) 90 days.

specimens without chemical corrosion show a ductile failure, and there is no instant drop of principal stress.

It can be seen in Figure 9 that the expansion path of the granite specimens is relatively bent. And a few of paths even deviate from the failure path. It is due to the heterogeneity of composition of granite. The strength of each composition is naturally different, and then, the resistance of fissured propagation of granites is also different.

3.2.2. Peak Strength and Elastic Modulus. To further study the effect of chemical corrosion on the mechanical properties of fissured granites, this paper selects the maximum value of the stress as the peak strength and approximately $40 \%$ to $60 \%$ of the linear part in the elastic stage of the stress-strain curve to calculate slope as the elastic modulus [34] by using the following formula:

$$
E=\frac{\sigma_{a 60}-\sigma_{a 40}}{\varepsilon_{a 60}-\varepsilon_{a 40}}
$$

where $\sigma_{a 40}$ and $\sigma_{a 60}$ are $40 \%$ and $60 \%$ of the peak strength, respectively. $\varepsilon_{a 40}$ and $\varepsilon_{a 60}$ are $40 \%$ and $60 \%$ of the axial strain in each stress-strain curve, respectively.

Figure 10 shows the variation curve of the elastic modulus of fissured granite with $\alpha=0^{\circ}, 30^{\circ}$, and $45^{\circ}$. Figure 11 shows the effect of prefabricated fissures on the peak strength of granite. The mechanical parameters are calculated, and the results are shown in Table 2. It is not difficult to find that the prefabricated fissures have a significant influence on the mechanical parameters of granite from the experimental results. As the fissured angles increase, the elastic modulus and peak strength both show a tendency to attenuate.

Based on the test results of stress-strain curves after chemical corrosion in Figure 8, it is indicated that the longer time granites are immersed in the chemical solution, the bigger chemical damage is acted on the granites. Therefore, chemical damage has a significant influence on the mechanical parameters of granite. The following part of this article explores the influence of chemical corrosion on the 


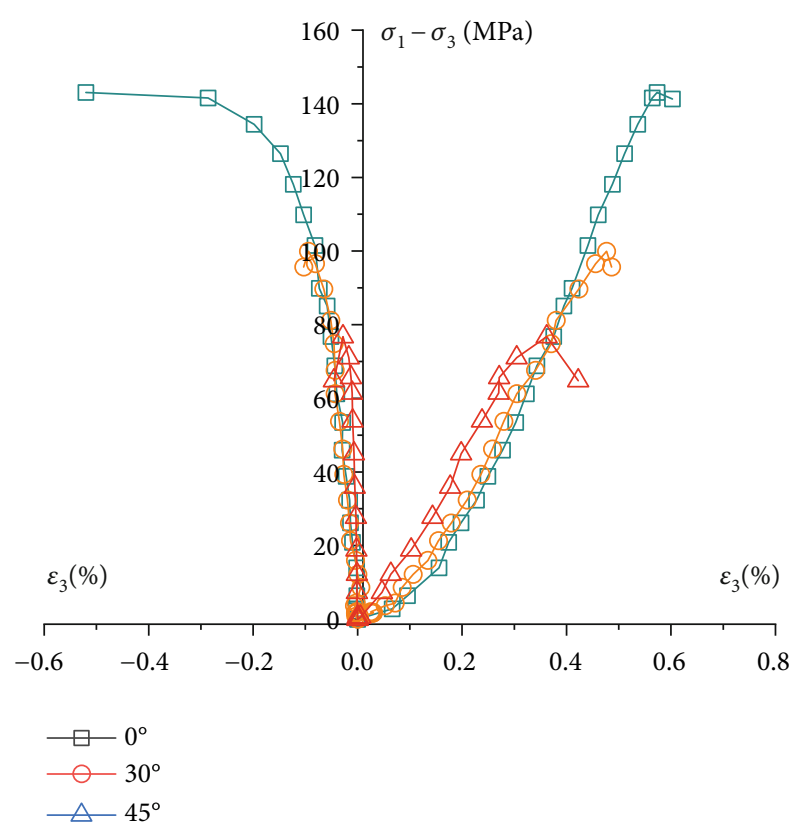

Figure 7: Stress-strain curves of fissured granites with $\alpha=0^{\circ}, 30^{\circ}$, and $45^{\circ}$ under the uniaxial compression test without chemical corrosion.

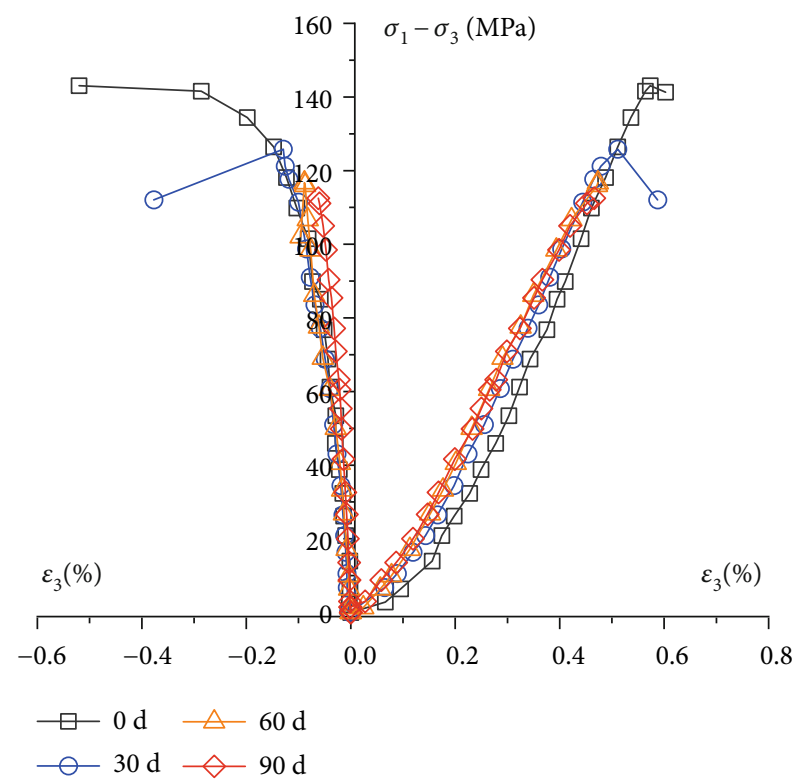

FIGURE 8: Stress-strain curves of fissured granites of uniaxial compression test under the action of chemical corrosion $\left(\alpha=0^{\circ}\right.$ specimen after chemical corrosion for 30,60 , and 90 days).

mechanical properties of fissured granites through the relevant mechanical parameters of granites.

Figure 12 shows the variation curves of elastic modulus of fissured granites with $\alpha=0^{\circ}, 30^{\circ}$, and $45^{\circ}$ after chemical corrosion for 30, 60, and 90 days. Figure 13 shows the variation curves of peak strength of fissured granites with $\alpha=0^{\circ}, 30^{\circ}$, and $45^{\circ}$ after chemical corrosion for 30,60 , and 90 days. It can be seen from Figures 12 and 13 that the mechanical

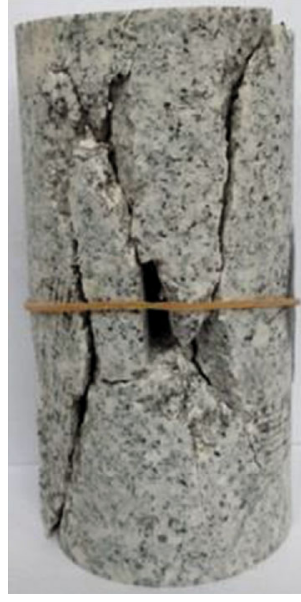

(a)

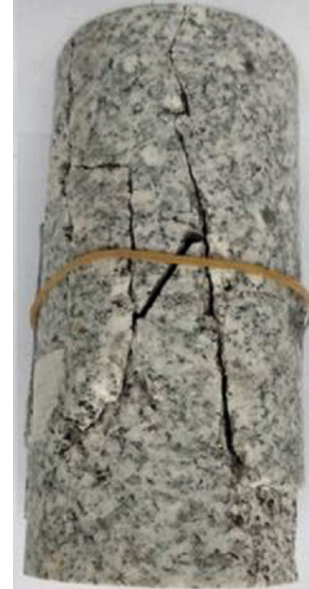

(b)

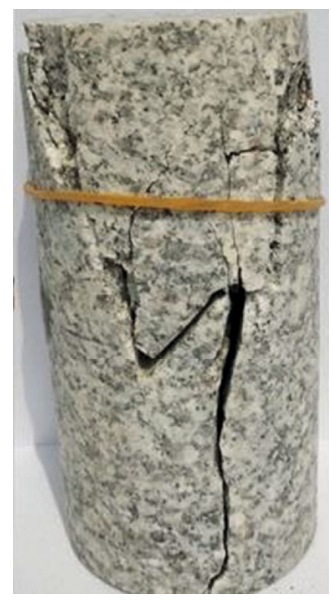

(c)

FIgURE 9: Crack initiation of prefabricated fissured granite with different inclination under the uniaxial compression test: (a) specimen with $\alpha=0^{\circ}$, (b) specimen with $\alpha=30^{\circ}$, and (c) specimen with $\alpha=45^{\circ}$.

parameters of prefabricated fissured granites with $\alpha=0^{\circ}$, $30^{\circ}$, and $45^{\circ}$ have changed to a certain extent after chemical corrosion for 30, 60, and 90 days. According to the above method of calculating the peak strength and elastic modulus, the mechanical parameters of the fissured granites after chemical corrosion for 30,60 , and 90 days are calculated. The results of peak strength and elastic modulus of fissured granite with $\alpha=0^{\circ}, 30^{\circ}$, and $45^{\circ}$ after chemical corrosion for 30,60 , and 90 days are recorded in Table 3.

As shown in Figure 13, after chemical corrosion for 30, 60 , and 90 days, the peak strength of prefabricated fissured granite with different inclination shows a decreasing trend on the whole. Through the experimental values of the peak strength in Table 3, it can be seen that the peak strength of specimens with $\alpha=0^{\circ}$ decreases from 140.88 to $112.50 \mathrm{MPa}$, and the degradation amplitude of the peak strength of the specimens with $\alpha=0^{\circ}$ is $10.60 \%, 17.17 \%$, and $20.14 \%$, respectively. The peak strength of specimens with $\alpha=30^{\circ}$ decreases from 100.73 to $85.34 \mathrm{MPa}$, and the degradation amplitude of the specimens with $\alpha=30^{\circ}$ is $9.22 \%, 10.20 \%$, and $15.28 \%$, respectively. The peak strength of specimens with $\alpha=45^{\circ}$ 


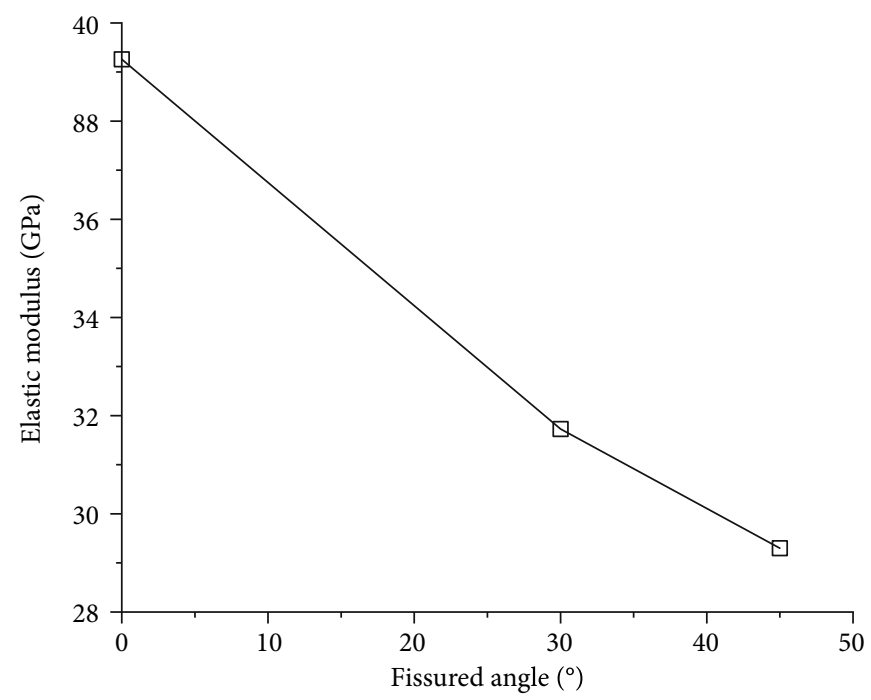

FIgURE 10: Variation of elastic modulus of fissured granites with $\alpha=0^{\circ}, 30^{\circ}$, and $45^{\circ}$.

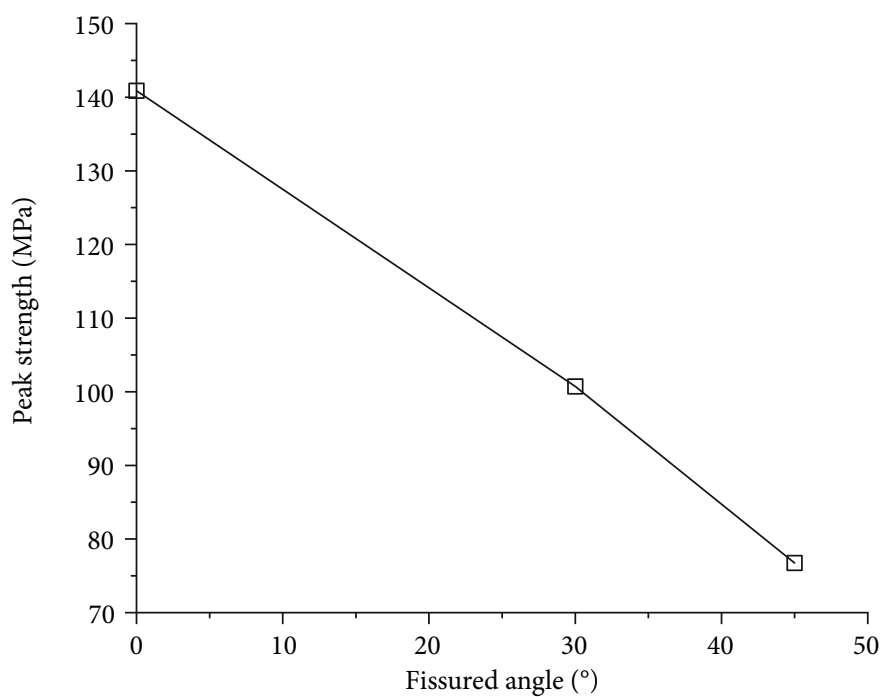

FIGURE 11: Variation of peak strength of fissured granites with $\alpha=0^{\circ}, 30^{\circ}$, and $45^{\circ}$.

TABLE 2: Results of fissured granites with different inclination under uniaxial compressive test.

\begin{tabular}{lcc}
\hline Fissured angle $\left(^{\circ}\right)$ & Peak strength $(\mathrm{MPa})$ & Elastic modulus $(\mathrm{GPa})$ \\
\hline 0 & 140.88 & 39.26 \\
30 & 100.73 & 31.73 \\
45 & 76.75 & 29.33 \\
\hline
\end{tabular}

decreases from 75.75 to $67.19 \mathrm{MPa}$, and the degradation amplitude of the specimens with $\alpha=45^{\circ}$ is $-0.12 \%, 7.92 \%$, and $12.46 \%$, respectively.

It can be seen from Figure 12 that the elastic modulus of granites with different inclinations show a gradually decreasing tendency with the increase of immersed time of chemical solution. Combined with the value of elastic modulus in Table 3, the average values of elastic modulus of specimens with $\alpha=0^{\circ}$ descend from 39.26 to $33.17 \mathrm{GPa}$ after the chemical corrosion for 90 days. And after chemical corrosion for 30, 60, and 90 days, the degradation amplitude of the elastic modulus of the specimens with $\alpha=0^{\circ}$ is $2.06 \%, 5.99 \%$, and $15.51 \%$, respectively. Granites with other fissured angles have similar results. For example, descending from 31.73 to $26.96 \mathrm{GPa}$, the degradation amplitude is $-1.70 \%, 10.53 \%$, and $15.03 \%$, respectively (specimens with $\alpha=30^{\circ}$ ). Descending from 29.33 to $21.91 \mathrm{GPa}$, the degradation amplitude is, respectively, $-3.10 \%, 10.47 \%$, and $25.30 \%$ (specimens with $\alpha=45^{\circ}$ ). Through the above analysis, it can be seen that the mechanical parameters of specimens with $\alpha=30^{\circ}$ and $\alpha=45^{\circ}$ slightly increase after chemical corrosion for 30 days. Because granite has the heterogeneity of material itself and the fissure has an error in size, the change of microstructure and the degree of corrosion softening are slightly different under the action of the chemical solution, leading to different mechanical characteristics of 


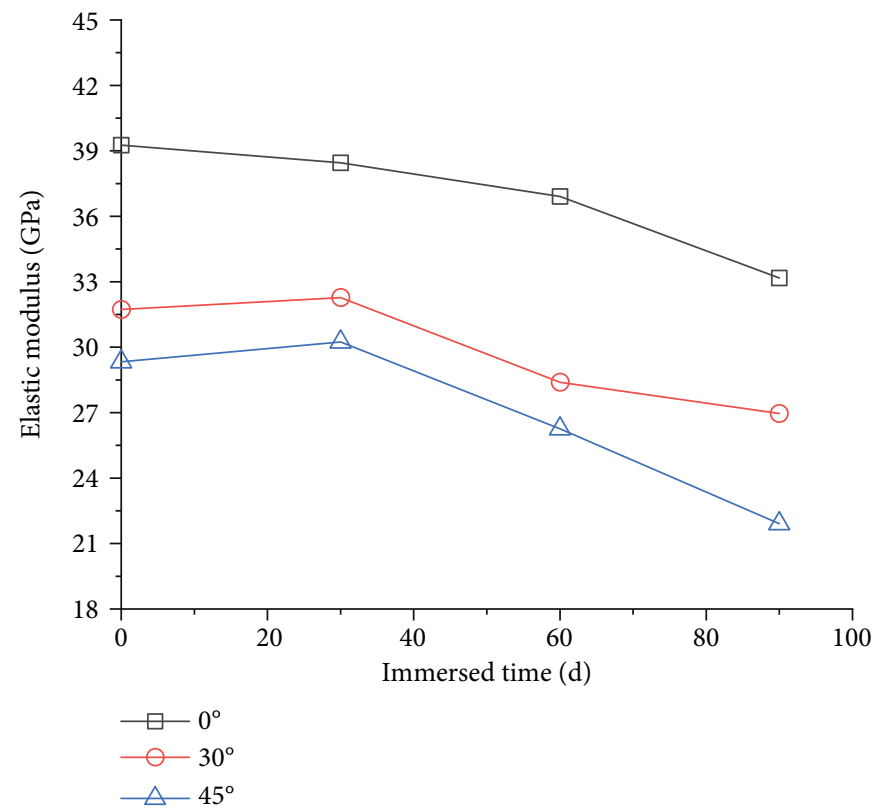

Figure 12: Variation of elastic modulus of fissured granite with $\alpha=0^{\circ}, 30^{\circ}$, and $45^{\circ}$ after chemical corrosion for 30,60 , and 90 days.

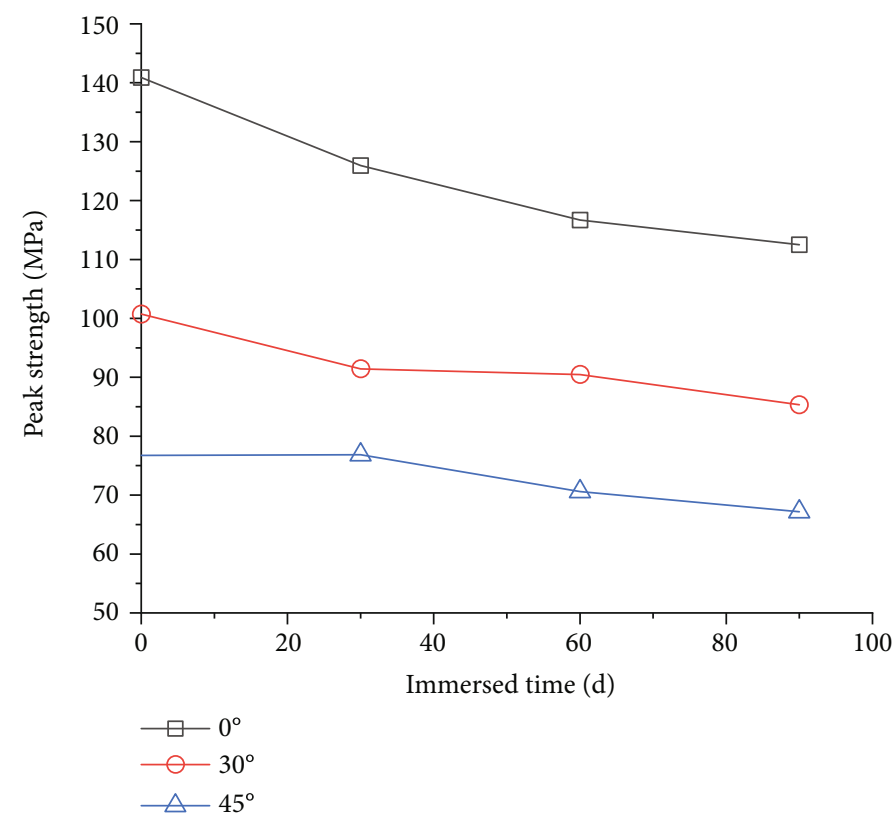

FIgURE 13: Variation of peak strength of fissured granite with $\alpha=0^{\circ}, 30^{\circ}$, and $45^{\circ}$ after chemical corrosion for 30,60 , and 90 days.

TABLE 3: The results of the uniaxial compression test of fissured granites under the action of chemical solution.

\begin{tabular}{lcccccc}
\hline $\begin{array}{l}\text { Immersed time } \\
(\mathrm{d})\end{array}$ & $\begin{array}{c}0^{\circ} \\
\text { Peak strength } \\
(\mathrm{MPa})\end{array}$ & $\begin{array}{c}\text { Elastic modulus } \\
(\mathrm{GPa})\end{array}$ & $\begin{array}{c}\text { Peak strength } \\
(\mathrm{MPa})\end{array}$ & $\begin{array}{c}\text { Elastic modulus } \\
(\mathrm{GPa})\end{array}$ & $\begin{array}{c}\text { Peak strength } \\
(\mathrm{MPa})\end{array}$ & $\begin{array}{c}\text { Elastic modulus } \\
(\mathrm{GPa})\end{array}$ \\
\hline 0 & 140.88 & 39.26 & 100.73 & 31.73 & 76.75 & 29.33 \\
30 & 125.94 & 38.45 & 91.44 & 32.27 & 76.84 & 70.61 \\
60 & 116.69 & 36.91 & 90.46 & 28.39 & 26.24 & 26.26 \\
90 & 112.50 & 33.17 & 85.34 & 26.96 & 67.19 & 21.91 \\
\hline
\end{tabular}




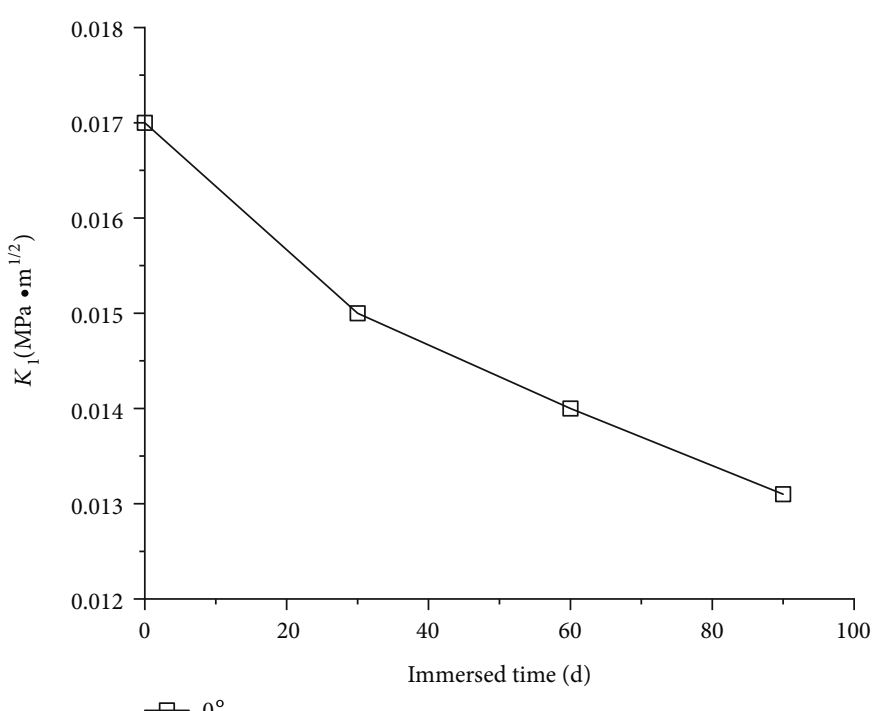

$\square 0^{\circ}$

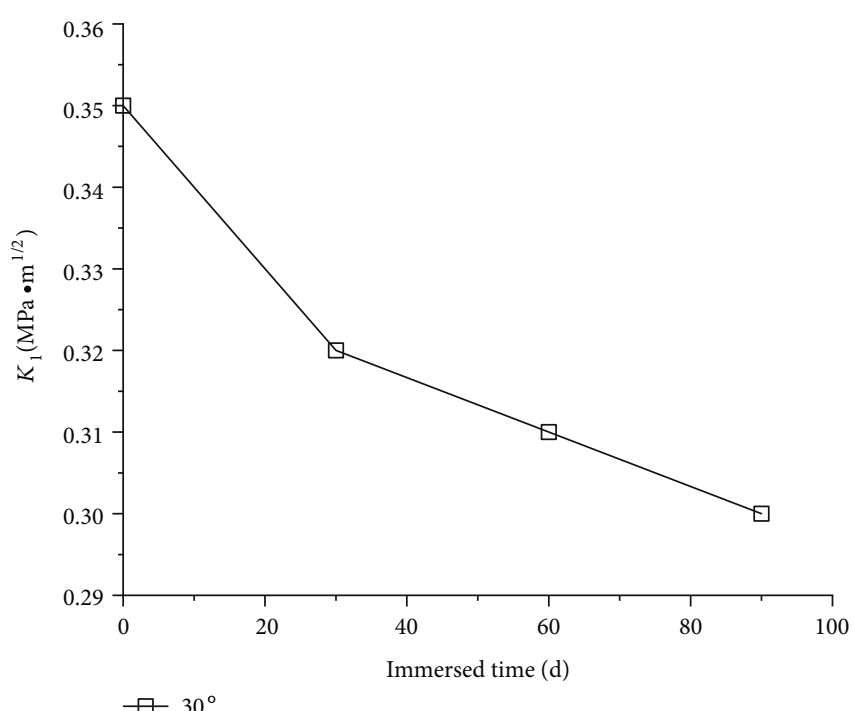

(b)

(a)

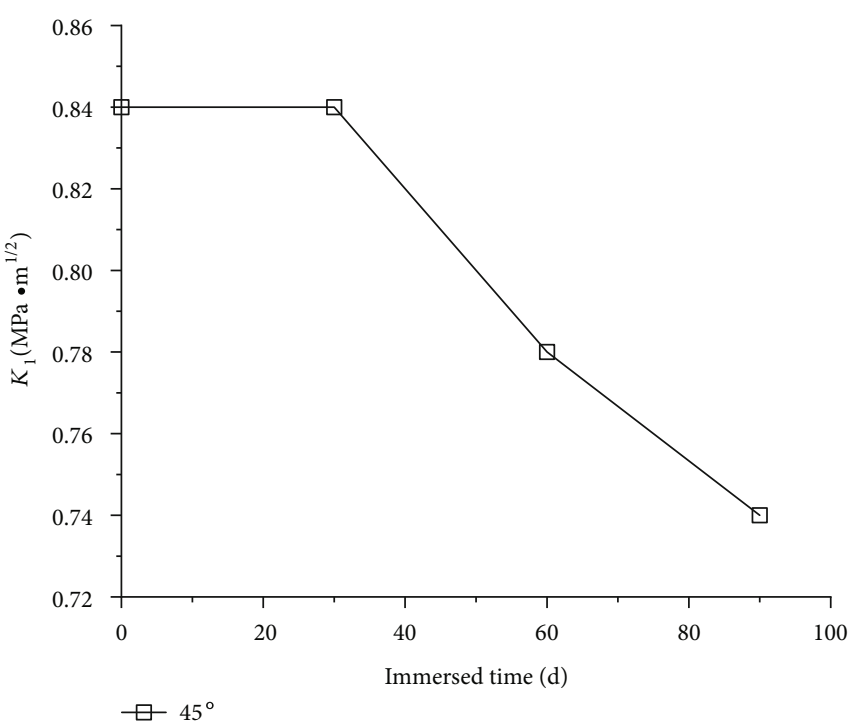

(c)

Figure 14: Variation of $K_{1}$ under the action of chemical solution.

some specimens and occurrence of discreteness phenomenon $[40,41]$.

\section{Discussion}

4.1. Evolutions of Stress Intensity Factors under the Action of Chemical Solution. In order to better understand the evolution of the stress field at the tip of the fissure after chemical corrosion, stress intensity factors are analyzed to investigate the effect of chemical solution on the fracture characteristics of fissured granite.

From previous research results, we can know that the process of failure of rock masses containing joints, I-type tensile failure, and II-type shear failure both exist, but II-type shear failure is difficult to observe [42]. More importantly, there is no clear boundary between the two destruction modes. Brace and Bombolakis [43] carried out tests on a glass model with prefabricated fissure and propose the slip-tension fracture model to study mechanical characteristics of brittle materials under the action of compression, which believes that I-type tensile failure is dominated in the mechanism of slip fracture. Therefore, the model of sliding fracture can better simulate the two types of shear-tension mixed failures in the process of compressive failure of granites. In the present work, an improved slipping crack model [44] is adopted, and the formula for stress intensity factors is written as

$$
\begin{aligned}
\frac{K_{1}}{\sigma_{1} \sqrt{\pi a}}= & \frac{-\mu[(1+\lambda)-(1-\lambda) \cos \gamma] \sin \gamma}{\pi \sqrt{L^{*}+L}} \\
& +\frac{(1-\lambda) \sin 2 \gamma \sin \gamma}{\pi \sqrt{L+L^{*}}}-\lambda \sqrt{L},
\end{aligned}
$$


where $K_{1}$ is the I-type strength stress factors, $\mu$ is the friction coefficient of the fissured surface, $\gamma$ is the angle of crack initiation, $L^{*}=8 /\left(3 \pi^{2}\right), L=l / a, l$ is the length of fissure after chemical corrosion, and $\lambda$ is the ratio of the confining pressure to the axial pressure. Considering the uniaxial compression testis applied in this work, a simplified formula of stress intensity factors is rewritten as

$$
\frac{K_{1}}{\sigma_{1} \sqrt{\pi a}}=\frac{-\mu[1-\cos \gamma] \sin \gamma}{\pi \sqrt{L+L^{*}}}+\frac{\sin 2 \gamma \sin \gamma}{\pi \sqrt{L+L^{*}}} .
$$

After the chemical corrosion, the extent of fissure growth is not obvious in the macroscopic view; therefore, the length of fissure is considered to be a constant during the chemical corrosion. According to Equation (8), the I-type stress intensity factors of specimens with $\alpha=0^{\circ}, 30^{\circ}$, and $45^{\circ}$ after chemical corrosion for 30,60 , and 90 days are calculated and the results are shown in Figure 14.

It can be seen from Figure 14 that the stress intensity factors of the specimens with $\alpha=0^{\circ}, 30^{\circ}$, and $45^{\circ}$ generally show the downward trend, as the immersed time of the chemical solution increases. And under the same chemical corrosion time, the changes in intensity factors of the specimens with $\alpha=45^{\circ}$ are the largest among the three angles.

4.2. Analysis of Mechanism of Stress Intensity Factors. The plastic zone of the fissured tip has a decisive effect in the fracture toughness of granite during the process of destruction of granite. When the chemical solution erodes the granite specimens, the chemical solution molecule is driven to the fissure of granites under the action of concentration gradient of chemical solution. The active ions of solution react with the mineral molecules such as adsorption reaction and hydration reaction. The chemical bond connecting with grains in the fissured tip appears fracture under the action of $\mathrm{H}^{+}$[45]. The process of water-rock reaction deteriorates the seepage channels of the fissured surface and the mechanical property of the fissured surface. The active ions in the chemical solution cause the mineral particles to migrate and dissolve, and form caves and microfissures inside the fissures, leading to an increase of porosity of the fissured surface, weaken the seepage performance and pore pressure of the fissured surface, and increase secondary pore [36]. Under the longterm chemical corrosion of the fissure tip of granite, microcracks both appear at the top and bottom of the fissures (see Figure 6), leading to a decrease of mechanical properties of the plastic zone at the fissured tip and increase of fissured length and a large quantity of stress concentration in the plastic zone [46]. Therefore, as the chemical corrosion time increases, the stress intensity factors at the fissure gradually decrease.

From a previous study, it can be known that as the fissured angle increases, the crack initiation stress becomes smaller, leading to initiate easily in the fissured tip. Simultaneously, a large number of cracks initiate, leading to stress concentration at the crack tip [47]. It is seen that there is no obvious stress concentration of specimens with $\alpha=0^{\circ}$ during the loading process (Figure 9(a)). The failure mode of the specimens with $\alpha=0^{\circ}$ is a simple compression failure and does not depend on the influence of the fissure. Consequently, the tension crack propagates along the direction of paralleling to prefabricated fissured surface. Nevertheless, the fissured granite of other angles reaches the crack initiation stress, and wing cracks and antiwing cracks gather and appear at the fissured tip, leading to stress concentration that occurs at the fissured tip (Figures 9(b) and 9(c)). As the loading progresses, the cracks penetrate and lead to the destruction of the specimens [48]. The stress intensity factors are a parameter that reflects the concentration of the stress field at the fissured tip. Therefore, from the above analysis, the specimen with $\alpha=0^{\circ}$ is a simple compression failure. There is almost no stress concentration at the prefabricated fissured tip. Therefore, the stress intensity factors of the specimens with $\alpha=0^{\circ}$ are the smallest or even close to 0 , while the specimens with $\alpha=30^{\circ}$ and $\alpha=45^{\circ}$ have a large quantity of stress concentration at the fissured tip, and the chemical corrosion has the largest effect on the intensity factors of the specimens with $\alpha=45^{\circ}$ among the three angles.

\section{Conclusions}

In this paper, granites are processed into three kinds of standard cylindrical fissured specimens with different inclinations. First, a chemical corrosion test is performed, and then, the specimens before and after immersion are proceeded to the uniaxial compression test. Based on the physical and mechanical experiment data of granite, this paper analyzes the damage effect of fissures on the mechanical properties of granite and chemical solutions on the physical and mechanical property of fissured granite. It is found that, during the immersed process, the $\mathrm{pH}$ value of the solution gradually becomes neutral and maintains at 4.1, and the mass loss gradually increases, and the $\mathrm{pH}$ value and rate of mass loss greatly change in the early immersed stage; the main mineral content of the fissured surface significantly changes. After the chemical corrosion, the surface of the fissure becomes loose and secondary micropore increases. As the time of chemical corrosion increases, the peak strength of fissured granite with $\alpha=0^{\circ}, 30^{\circ}$, and $45^{\circ}$ has decreased in varying degrees (from 140.88, 100.73, and 76.75 to 112.50 , 85.34, and $67.19 \mathrm{MPa}$, respectively). Simultaneously, the modulus of fissured granites with $\alpha=0^{\circ}, 30^{\circ}$, and $45^{\circ}$ also shows similar variation trends (from 39.26, 31.73, and 29.33 to $33.17,26.96$, and $21.91 \mathrm{GPa}$, respectively). Furthermore, the chemical corrosion shortens the compaction stage of the fissured granite, reduces the elastic stage of the fissured granite, and accelerates the failure of fissured granite. The stress intensity factors of the specimens with $\alpha=0^{\circ}, 30^{\circ}$, and $45^{\circ}$ decrease from $0.017,0.35$, and 0.84 to $0.013,0.30$, and $0.74 \mathrm{MPa} \cdot \mathrm{m}^{1 / 2}$, respectively, as the time of the chemical corrosion increases, and the chemical corrosion has the largest effect on the intensity factors of the specimens with $\alpha=45^{\circ}$ among the three kinds of specimens.

\section{Data Availability}

All the data used to support the findings of this study are included within the article. 


\section{Conflicts of Interest}

The authors have declared that we have no financial and personal relationships with other people or organizations that can inappropriately influence our work.

\section{Acknowledgments}

This work was jointly supported by the National Key Research and Development Program of China (Nos. 2018YFC0809600 and 2018YFC0809601), the Natural Science Foundation of China (grant numbers 51979100 and 51779252), and the Major Technological Innovation Projects of Hubei (No. 2017AAA128).

\section{References}

[1] Y. Ichikawa, K. Kawamura, K. Uesugi, Y. S. Seo, and N. Fujii, "Micro- and macrobehavior of granitic rock: observations and viscoelastic homogenization analysis," Computer methods in applied mechanics and engineering, vol. 191, no. 1-2, pp. 4772, 2001.

[2] M. Prudencio and M. van Sint Jan, "Strength and failure modes of rock mass models with non-persistent joints," International Journal of Rock Mechanics and Mining Sciences, vol. 44, no. 6, pp. 890-902, 2007.

[3] S. Q. Yang, X. R. Liu, and H. W. Jing, "Experimental investigation on fracture coalescence behavior of red sandstone containing two unparallel fissures under uniaxial compression," International Journal of Rock Mechanics and Mining Sciences, vol. 63, pp. 82-92, 2013.

[4] S. Q. Yang, Y. H. Huang, and P. G. Ranjith, "Failure mechanical and acoustic behavior of brine saturated-sandstone containing two pre-existing flaws under different confining pressures," Engineering Fracture Mechanics, vol. 193, pp. 108-121, 2018.

[5] L. N. Germanovich, R. L. Salganik, A. V. Dyskin, and K. K. Lee, "Mechanisms of brittle fracture of rock with pre-existing cracks in compression," Pure and Applied Geophysics, vol. 143, no. 1-3, pp. 117-149, 1994.

[6] A. Bobet, "The initiation of secondary cracks in compression," Engineering Fracture Mechanics, vol. 66, no. 2, pp. 187-219, 2000.

[7] W. Han, Y. Jiang, H. Luan, Y. du, Y. Zhu, and J. Liu, "Numerical investigation on the shear behavior of rock-like materials containing fissure-holes with FEM-CZM method," Computers and Geotechnics, vol. 125, article 103670, 2020.

[8] R. H. C. Wong, C. M. Law, K. T. Chau, and W. S. Zhu, "Crack propagation from 3-D surface fractures in PMMA and marble specimens under uniaxial compression," International Journal of Rock Mechanics and Mining Sciences, vol. 41, no. 3, pp. 3742, 2004.

[9] H. Lee and S. Jeon, "An experimental and numerical study of fracture coalescence in pre-cracked specimens under uniaxial compression," International Journal of Solids and Structures, vol. 48, no. 6, pp. 979-999, 2011.

[10] B. Vásárhelyi and A. Bobet, "Modeling of crack initiation, propagation and coalescence in uniaxial compression," Rock Mechanics and Rock Engineering, vol. 33, no. 2, pp. 119-139, 2000.
[11] R. H. C. Wong, K. T. Chau, C. A. Tang, and P. Lin, "Analysis of crack coalescence in rock-like materials containing three flaws- part I: experimental approach,” International Journal of Rock Mechanics and Mining Sciences, vol. 38, no. 7, pp. 909-924, 2001.

[12] P. Yin, R. H. C. Wong, and K. T. Chau, "Coalescence of two parallel pre-existing surface cracks in granite," International Journal of Rock Mechanics and Mining Sciences, vol. 68, pp. 66-84, 2014.

[13] T. H. Wu, Y. T. Gao, Y. Zhou, and J. Li, "Experimental and numerical study on the interaction between holes and fissures in rock-like materials under uniaxial compression," Theoretical and Applied Fracture Mechanics, vol. 106, article 102488, 2020.

[14] W. Yao, Y. Cai, J. Yu, J. Zhou, S. Liu, and B. Tu, "Experimental and numerical study on mechanical and cracking behaviors of flawed granite under triaxial compression," Measurement, vol. 145, pp. 573-582, 2019.

[15] S. Mondal, L. Olsen-Kettle, and L. Gross, "Simulating damage evolution and fracture propagation in sandstone containing a preexisting 3-d surface flaw under uniaxial compression," International Journal for Numerical and Analytical Methods in Geomechanics, vol. 43, no. 7, pp. 1448-1466, 2019.

[16] M. Rezania, M. Panahandeh, S. M. J. Razavi, and F. Berto, "Experimental study of the simultaneous effect of nano-silica and nano-carbon black on permeability and mechanical properties of the concrete," Theoretical and Applied Fracture Mechanics, vol. 104, article 102391, 2019.

[17] S. Q. Yang, T. Xu, L. He, H. W. Jing, S. Wen, and Q. L. Yu, "Numerical study on failure behavior of brittle rock specimen containing pre- existing combined flaws under different confining pressure," Archives of Civil and Mechanical Engineering, vol. 15, no. 4, pp. 1085-1097, 2015.

[18] S. Xie and J. Shao, "Elastoplastic deformation of a porous rock and water interaction," International Journal of Plasticity, vol. 22, no. 12, pp. 2195-2225, 2006.

[19] B. K. Atkinson and P. G. Meredith, "Stress corrosion cracking of quartz: a note on the influence of chemical environment," Tectonophysics, vol. 77, no. 1-2, pp. T1-T11, 1981.

[20] J. Dunning, B. Douglas, M. Miller, and S. McDonald, "The role of the chemical environment in frictional deformation: stress corrosion cracking and comminution," Pure and Applied Geophysics, vol. 143, no. 1-3, pp. 151-178, 1994.

[21] M. G. Karfakis and M. Akram, "Effects of chemical solutions on rock fracturing," International journal of rock mechanics and mining sciences \& geomechanics abstracts, vol. 30, no. 7, pp. 1253-1259, 1993.

[22] J. Sausse, E. Jacquot, B. Fritz, J. Leroy, and M. Lespinasse, "Evolution of crack permeability during fluid-rock interaction. Example of the Brezouard granite (Vosges, France)," Tectonophysics, vol. 336, no. 1-4, pp. 199-214, 2001.

[23] K. B. Min, J. Rutqvist, and D. Elsworth, "Chemically and mechanically mediated influences on the transport and mechanical characteristics of rock fractures," International Journal of Rock Mechanics and Mining Sciences, vol. 46, no. 1, pp. 80-89, 2009.

[24] D. Croizé, K. Bjørlykke, J. Jahren, and F. Renard, "Experimental mechanical and chemical compaction of carbonate sand," Journal of Geophysical Research: Solid Earth, vol. 115, no. B11, 2010.

[25] L. Yu, Z. Zhang, J. Wu, R. Liu, H. Qin, and P. Fan, "Experimental study on the dynamic fracture mechanical properties of 
limestone after chemical corrosion," Theoretical and Applied Fracture Mechanics, vol. 108, article 102620, 2020.

[26] A. Ghazvinian, V. Sarfarazi, W. Schubert, and M. Blumel, “A study of the failure mechanism of planar non-persistent open joints using PFC2D," Rock Mechanics and Rock Engineering, vol. 45, no. 5, pp. 677-693, 2012.

[27] S. Portier and F. D. Vuataz, "Developpement des capacites de modelisation des interactions acides-roche et des dissolutions de mineraux au cours des tests de stimulation acide de type RMA realises sur le site SGS de Soultz-sous-Forets (France)," Comptes Rendus Geoscience, vol. 342, no. 7-8, pp. 668-675, 2010.

[28] D. O. Potyondy, "Simulating stress corrosion with a bondedparticle model for rock," International Journal of Rock Mechanics and Mining Sciences, vol. 44, no. 5, pp. 677-691, 2007.

[29] S. G. Li, R. K. Huo, B. Wang et al., "Experimental study on physicomechanical properties of sandstone under acidic environment," Advances in Civil Engineering, vol. 2018, Article ID 5784831, 15 pages, 2018.

[30] E. Mohtarami, A. Baghbanan, M. Eftekhari, and H. Hashemolhosseini, "Investigating of chemical effects on rock fracturing using extended finite element method," Theoretical and Applied Fracture Mechanics, vol. 89, pp. 110-126, 2017.

[31] S. H. Hoseinie, M. Ataei, and R. Mikaiel, "Comparison of some rock hardness scales applied in drillability studies," Arabian Journal for Science and Engineering, vol. 37, no. 5, pp. 14511458, 2012.

[32] G. Aydin, I. Karakurt, and K. Aydiner, "An investigation on surface roughness of granite machined by abrasive waterjet," Bulletin of materials science, vol. 34, no. 4, pp. 985-992, 2011.

[33] V. Sunitha, B. M. Reddy, J. A. Khan, and M. R. Reddy, "Groundwater geochemistry in the southeastern part of Anantapur District, Andhra Pradesh, with special reference to fluoride distribution and its impact on health," Journal of Environmental Science \& Engineering, vol. 56, no. 2, pp. 153-160, 2014.

[34] F. Zhang, J. Zhao, D. Hu, F. Skoczylas, and J. Shao, "Laboratory investigation on physical and mechanical properties of granite after heating and water-cooling treatment," Rock Mechanics and Rock Engineering, vol. 51, no. 3, article 1350, pp. 677694, 2018.

[35] H. Li, I. I. Eshiet, Y. Sheng, Z. Zhong, X. Liu, and D. Yang, “A parallel-bonded chemical corrosion model for discrete element modelling of chemically corroded limestone," Engineering Fracture Mechanics, vol. 202, pp. 297-310, 2018.

[36] S. Miao, M. Cai, Q. Guo, P. Wang, and M. Liang, "Damage effects and mechanisms in granite treated with acidic chemical solutions," International Journal of Rock Mechanics and Mining Sciences, vol. 88, pp. 77-86, 2016.

[37] F. Zhang, J. Zhao, D. Hu, Q. Sheng, and J. Shao, "Creep strain and permeability evolution in cracked granite subjected to triaxial stress and reactive flow," Geofluids, vol. 2018, Article ID 4653937, 10 pages, 2018 .

[38] R. H. Lander and L. M. Bonnell, "A model for fibrous illite nucleation and growth in sandstones," AAPG bulletin, vol. 94, no. 8, pp. 1161-1187, 2010.

[39] R. H. Worden and S. Morad, "Clay minerals in sandstones: controls on formation, distribution and evolution," Interna- tional Association of Sedimentologists. Special Publication, vol. 34, pp. 3-42, 1999.

[40] Y. Ju, K. Luxbacher, X. Li et al., "Micro-structural evolution and their effects on physical properties in different types of tectonically deformed coals," International Journal of Coal Science \& Technology, vol. 1, no. 3, pp. 364-375, 2014.

[41] S. J. Miao, X. P. Lai, X. G. Zhao, and F. H. Ren, "Simulation experiment of AE-based localization damage and deformation characteristic on covering rock in mined-out area," International Journal of Minerals, Metallurgy and Materials, vol. 16, no. 3, pp. 255-260, 2009.

[42] A. Bobet and H. H. Einstein, "Fracture coalescence in rocktype materials under uniaxial and biaxial compression," International Journal of Rock Mechanics and Mining Sciences, vol. 35, no. 7, pp. 863-888, 1998.

[43] W. F. Brace and E. G. Bombolakis, "A note on brittle crack growth in compression," Journal of Geophysical Research, vol. 68, no. 12, pp. 3709-3713, 1963.

[44] J. M. Kemeny, "A model for non-linear rock deformation under compression due to sub-critical crack growth," International journal of rock mechanics and mining sciences \& geomechanics abstracts, vol. 28, no. 6, pp. 459-467, 1991.

[45] A. E. Blum and A. C. Lasaga, "The role of surface speciation in the dissolution of albite," Geochimica et Cosmochimica Acta, vol. 55, no. 8, pp. 2193-2201, 1991.

[46] Y. Cai, J. Yu, G. F. Fu, and H. Li, "Experimental investigation on the relevance of mechanical properties and porosity of sandstone after hydrochemical erosion," Journal of Mountain Science, vol. 13, no. 11, pp. 2053-2068, 2016.

[47] S. Q. Yang, "Crack coalescence behavior of brittle sandstone samples containing two coplanar fissures in the process of deformation failure," Engineering Fracture Mechanics, vol. 78, no. 17, pp. 3059-3081, 2011.

[48] C. H. Park and A. Bobet, "Crack initiation, propagation and coalescence from frictional flaws in uniaxial compression," Engineering Fracture Mechanics, vol. 77, no. 14, pp. 2727$2748,2010$. 